\title{
Transformative spaces in the making: key lessons from nine cases in the Global South
}

\author{
Laura Pereira, ${ }^{1,2,3}$ - Niki Frantzeskaki ${ }^{4}$. Aniek Hebinck ${ }^{5} \cdot$ Lakshmi Charli-Joseph $^{6} \cdot$ Scott Drimie $^{1,7} \cdot$ Michelle Dyer $^{3,8}$. \\ Hallie Eakin ${ }^{9} \cdot$ Diego Galafassi $^{3} \cdot$ Timos Karpouzoglou $^{10} \cdot$ Fiona Marshall $^{11} \cdot$ Michele-Lee Moore $^{3} \cdot$ Per Olsson ${ }^{3}$. \\ J. Mario Siqueiros-García ${ }^{6,12} \cdot$ Patrick van Zwanenberg ${ }^{13} \cdot$ Joost $M$. Vervoort ${ }^{14,15,16}$
}

Received: 11 April 2019 / Accepted: 22 October 2019 / Published online: 8 November 2019

(c) The Author(s) 2019

\begin{abstract}
Creating a just and sustainable planet will require not only small changes, but also systemic transformations in how humans relate to the planet and to each other, i.e., social-ecological transformations. We suggest there is a need for collaborative environments where experimentation with new configurations of social-ecological systems can occur, and we refer to these as transformative spaces. In this paper, we seek a better understanding of how to design and enable the creation of transformative spaces in a development context. We analyse nine case studies from a previous special issue on Designing Transformative Spaces that aimed to collect examples of cutting-edge action-oriented research on transformations from the Global South. The analysis showed five design phases as being essential: Problem Definition Phase; Operationalisation Phase; Tactical Phase; Outcome Phase; and Reflection Phase. From this synthesis, we distilled five key messages that should be considered when designing research, including: (a) there are ethical dilemmas associated with creating a transformative space in a system; (b) it is important to assess the readiness of the system for change before engaging in it; (c) there is a need to balance between 'safe' and 'safe-enough' spaces for transformation; (d) convening a transformative space requires an assemblage of diverse methodological frameworks and tools; and (e) transformative spaces can act as a starting point for institutionalising transformative change. Many researchers are now engaging in transdisciplinary transformations research, and are finding themselves at the knowledge-action interface contributing to transformative space-making. We hope that by analysing experiences from across different geographies we can contribute towards better understanding of how to navigate the processes needed for the urgent global transformations that are being called for to create a more equitable and sustainable planet Earth.
\end{abstract}

Keywords Co-production $\cdot$ Facilitation $\cdot$ Global South $\cdot$ Sustainability $\cdot$ Transdiciplinarity $\cdot$ Transformation

\section{Introduction}

The advent of the Anthropocene-where humans have become the dominant force of change on the planet-brings complex social-ecological challenges that require humanity to engage with the world and with each other in new ways (Pereira et al. 2015; Steffen et al. 2015; Preiser et al. 2017). Creating a more just and sustainable planet will require not only small changes, but systemic, social-ecological

Handled by David J. Abson, Leuphana Universitat Luneburg, Germany.

Laura Pereira

Pereira.laura18@gmail.com

Extended author information available on the last page of the article transformations. Greater political equity and inclusion of diverse stakeholders in co-constructing new knowledges, and opening up dialogues for change are imperative for finding ways forward (Scoones et al. 2018). With this comes an urgent need for researchers to engage seriously with the critical question of how to contribute to making transformative change happen (Fazey et al. 2018). Many alternative forms of research that are democratic, inclusive, action-oriented and integrate different forms of knowledge have emerged over the last three decades, including mode 2 , transdisciplinarity, post-normal, participatory, sustainability science and action research, but these are not necessarily focused on facilitating transformative changes to achieve a more sustainable and just future (Fazey et al. 2018). New transdisciplinary processes for initiating and supporting transformative change will need to build on and include existing practices 
Table 1 Case studies and their geographical setting

\begin{tabular}{ll}
\hline Case title & Geography \\
\hline Xochimilco wetland (Charli-Joseph et al. 2018) & Xochimilco urban wetland, Mexico City \\
Argentinian seeds (van Zwanenberg et al. 2018) & Argentina \\
Food system futures (Hebinck et al. 2018) & Eindhoven (Netherlands), Tuscany (Italy), Burkina Faso, Tanzania \\
Good anthropocenes (Pereira et al. 2018a) & Southern Africa \\
Stories for co-creation (Galafassi et al. 2018) & Mombasa (Southern coast of Kenya), Cabo Delgado (Northern coast of Mozambique) \\
Transdisciplinary research (Marshall et al. 2018) & Peri-urban South Asia \\
Southern Africa Food lab (Drimie et al. 2018) & South Africa, particularly Mopani District in Limpopo and the site of the agro-ecology \\
& and leadership training facility in Soweto \\
Global fellowship (Moore et al. 2018) & Global, with strong emphasis on Africa, South and Southeast Asia, and South America \\
Gender meetings (Dyer 2018) & Western Province, Solomon Islands \\
\hline
\end{tabular}

such as experimentation in public engagement, multi-stakeholder dialogues and knowledge co-production strategies that generate inclusive systemic solutions. However, the explicit framing of the need for transformative change in light of complex social-ecological challenges necessitates moving into a new kind of transdisciplinarity that is action oriented as well as co-produced, while remaining grounded in research. It is from this perspective that we propose a new setting for such processes: transformative spaces.

We define transformative spaces as collaborative environments where experimentation with new configurations of social-ecological systems, crucial for transformation, can occur (Pereira et al. 2018b). Transformative spaces allow and enable dialogue, reflection and reflexive learning, while reframing issues in ways that allow solutions - or at the very least, attempts to experiment and transform-to be co-created and co-realised. As such, they deliberately seek a variety of perspectives aside from those that usually dominate. They also seek to operate as stepping stones for Social-Ecological System (SES) transformations that are attentive to the specifics of the context in which the space is being convened. In this context, we refer to 'safe enough' spaces rather than 'safe spaces'. We use this term to encapsulate that while it is essential to create a level of openness and trust while convening these spaces, there is also sometimes a level of discomfort for participants. We acknowledge that all spaces of stakeholder interaction remain political, and that discussing and co-creating transformation pathways to sustainable and just futures will always be contested (Zgambo 2018). Discomfort for more powerful actors within a space may in some instances also reduce the safety of others (Drimie et al. 2018). Doing something other than 'business as usual' is likely to be uncomfortable for most, at least initially.

The complex social-ecological challenges facing the planet have resulted in an increased focus on the co-creation and co-production of knowledge or, transdisciplinarity (Pohl et al. 2010; Lemos et al. 2018). In part, these approaches are a reaction to the challenges of fast changing complex systems, but the result is that the role of the researcher solely as a provider of knowledge becomes increasingly blurred (Milkoreit et al. 2015; Wittmayer and Schäpke 2014). While researchers arguably have always been more than only knowledge providers, the interest of research in the application of that knowledge, and in the outcomes and impacts that arise from spaces facilitated by researchers-like stronger networks, actionable plans and policy interventions-is a more recent phenomenon (see for e.g., Frantzeskaki et al. 2014; Wittmayer and Schäpke 2014; Luederitz et al. 2017; Schäpke et al. 2018). This research that elucidates the complex dynamics of researchers as knowledge providers stems predominantly from the Global North. There is thus a gap in knowledge concerning lessons and implications as well as conceptual contributions to this thinking from Southern contexts. Building on this nascent, but growing body of work that attempts to characterize these transdisciplinary and potentially transformative efforts, we provide insights from the synthesis of nine cases predominantly in the Global South where attempts were made to create transformative spaces.

We believe that by focusing on cases from the Global South we can further advance efforts of scholars such as Mukute and Lotz-Sisitka (2012) and Bosch et al. (2013) to unpack complexity and understand better the contextspecific and precarious social-ecological issues that may be more prevalent in these regions (Pereira et al. 2018b). Further, we hope to make explicit recommendations on how better to design experimental processes and institutional spaces that will progress both research and practice on the transformations that are needed globally, with inclusion of evidence from the South. The author team is a mix of scholars from the North and the South, and we acknowledge that this does not come without sets of diverse assumptions and challenges. However, through this synthesis we have aimed to engage in a different way of working together to integrate perspectives from all parts of the world, without one dominating over the other. 
Table 2 Transformative spaces framework used to guide case study design and realisation as co-created in the first author workshop

\begin{tabular}{|c|c|c|}
\hline Design phase & Central concepts and issues to consider & Guiding questions per phase \\
\hline Problem Definition Phase & $\begin{array}{l}\text { Central concepts: } \\
\text { Objectives } \\
\text { Problem space } \\
\text { Theory of change } \\
\text { Issues to consider: } \\
\text { Horns of the dilemma } \\
\text { Maladaptive states } \\
\text { Lock-ins }\end{array}$ & $\begin{array}{l}\text { What are the purposes and goals of your } \\
\text { project? } \\
\text { What is the problem addressed? } \\
\text { Why is it a problem? } \\
\text { What are the conflicting issues or different } \\
\text { perspectives of the problem? } \\
\text { What change do you expect during the course } \\
\text { of the convened process? }\end{array}$ \\
\hline $\begin{array}{l}\text { Operationalisation Phase: Process and conven- } \\
\text { ing }\end{array}$ & $\begin{array}{l}\text { Central concepts: } \\
\text { Types of participants } \\
\text { Quality of participation } \\
\text { Issues to consider: } \\
\text { Power relations } \\
\text { Sectors, perspectives } \\
\text { Incentives and ethics of engagement }\end{array}$ & $\begin{array}{l}\text { Who do you need to have in the space? } \\
\text { What are the dynamics between these actors? } \\
\text { How do you engage and motivate actors to } \\
\text { participate in the process? }\end{array}$ \\
\hline Tactical Phase: Methods and Tools & $\begin{array}{l}\text { Central concepts: } \\
\text { Understanding change } \\
\text { Measuring impact } \\
\text { Experiential learning } \\
\text { Appreciative enquiry } \\
\text { Learning journeys } \\
\text { Issues to consider: } \\
\text { Sensitive controversial topics }\end{array}$ & $\begin{array}{l}\text { What were the specific facilitation tools you } \\
\text { employed or created to enable the co-design } \\
\text { process? } \\
\text { Why were these employed? How did they help } \\
\text { to address the types of issues raised? } \\
\text { What conflicts/sensitive issues/confusion } \\
\text { emerged and how were these dealt with? } \\
\text { What was the impact of the tools on the } \\
\text { process? } \\
\text { What tools did you use to evaluate the impact } \\
\text { of the process? }\end{array}$ \\
\hline $\begin{array}{l}\text { Outcomes Phase: Measuring impacts of trans- } \\
\text { formative change }\end{array}$ & $\begin{array}{l}\text { Central concepts: } \\
\text { Unpacking success } \\
\text { Changes in behaviour, perceptions, mind-sets, } \\
\text { values, beliefs } \\
\text { Issues to consider: } \\
\text { Cross-level impacts } \\
\text { Uncertainties and unknowns }\end{array}$ & $\begin{array}{l}\text { Were the expected outcomes met? } \\
\text { What were the unexpected outcomes? } \\
\text { What changed as a result of the project at the } \\
\text { individual level, the collective level and at } \\
\text { the systems level? } \\
\text { How do changes at individual, collective and } \\
\text { systems level interrelate? }\end{array}$ \\
\hline Reflection Phase & $\begin{array}{l}\text { Central concepts: } \\
\text { Contribution to the field } \\
\text { Further research } \\
\text { Issues to consider: } \\
\text { Socia-cultural and ecological dynamics and } \\
\text { diversity }\end{array}$ & $\begin{array}{l}\text { What are the remaining unknowns? } \\
\text { What worked? What didn't work? What were } \\
\text { you expecting to be able to change, and what } \\
\text { did you actually change? } \\
\text { What is the role of power dynamics/represen- } \\
\text { tivity in transformation? } \\
\text { Why would you call your project a transforma- } \\
\text { tive space? }\end{array}$ \\
\hline
\end{tabular}

Each of the nine case studies are published in a special issue on Designing Transformative Spaces (Table 1). The Special Issue aimed to collect examples of cutting-edge, actionoriented research on transformations from the Global South. However, through that process, we believed it was important then to take a further step to analyse cross-cutting themes and provide a synthesis. Through our synthesis discussion, key areas of interest emerged: the interactive engagement between stakeholders and researchers, the deepening of multi-actor collaboration, the facilitation of transdisciplinary knowledge co-production, inclusivity and depth of participation, and sense-making where individuals cognitively relate to others and their environment. Through the analysis, we focused on five general design phases that could be recognized as important in transformative spaces: (a) Problem Definition Phase; (b) Operationalisation Phase; (c) Tactical Phase; (d) Outcome Phase; and (e) Reflection Phase (see Table 2). Our findings then focus on lessons from the meta-analysis of these nine cases and across these five phases to help guide future research and experimental practice in engaging with actors across public, private and civil society sectors in designing and facilitating systemic change efforts within transformative spaces. Thus, this article aims to contribute to fostering and instigating social-ecological innovations that contribute purposively to transformations. 


\section{Context: focus on the global south}

Social-ecological transformations have largely been formulated and debated in the conceptual frameworks and contexts of the Global North (Pereira et al. 2015). For example, while many of the sustainability challenges and opportunities around urbanisation are located in the diverse contexts of the Global South, most of our knowledge on urban areas comes from the perspective of the Global North (Nagendra et al. 2018). Structural biases in global knowledge production systems mean the strong imperatives and unique capacities of the Global South to innovate, experiment for sustainability and nurture transformative trajectories remain under researched and often overlooked, despite their potential broadly to inform transformative processes across the world (Nagendra et al. 2018; Marshall and Dolley 2019).

In using the term "Global South", we recognize that we are not referring to a homogeneous entity; rather, it is varied, diverse, and fast changing. For example, there are areas facing extremes in terms of social, political, economic circumstances, often tied to environmental change and injustices associated with histories of resource extraction (Omeje 2017). Here, populations are more likely to be facing (or recovering from) highly volatile political and economic circumstances (World Bank 2011), and face more stark contexts of inequality and disenfranchisement (Hickel 2016). Governance at the level of the nationstate that has failed to enable welfare improvement of the majority is common in many post-colonial countries in the Global South (Börzel and Risse 2010; Hickel 2012).

Failures of imposed political structures in the shape of the nation-state can be partly attributed to a bad fit with previous indigenous and traditional political institutions, authority centres and decision-making practices (see Mbembe 2000; Morgan 2005; Dinnen and Firth 2008). Prior to nation-state delineations, groups within most of these countries did not operate under a centralized authority that cut across tribal, religious and other affiliations. This is visible in the current evidence of local action and autonomous efforts, that spring not only from weaknesses in neo-colonial political institutions, but also from autochthonous power structures (Börzel and Risse 2010). A reliance on alternative power structures means that people in different social, economic and political conditions have already developed strategies to take advantage of the inadequacies in current power structures (Menkhaus 2007). In this context, transformation processes may seem threatening because they represent breaking down many of the constraints that keep business as usual conditions that often support elite capture of benefits (van Breda and Swilling 2019).
Diverse knowledge systems and ways of being in the world and understanding complex human-environment relationships arise in the Global South. Although colonisation aimed to impose Western thinking and institutions on many of these areas, indigenous, local and syncretic knowledge systems continue to operate and can provide inputs for new framings of how people relate to each other and to nature in complex, more systemic configurations (Tengö et al. 2014; Díaz et al. 2015). This historical, context-specific knowledge and its ability to counter more extractive ideas of human-environmental relations is an important source for potential solutions to the social-ecological challenges of the Anthropocene (Brondizio et al. 2016).

\section{Methods}

This paper draws from a set of nine case studies on transformative spaces that formed part of a special issue in Ecology and Society (Table 1). The process through which cases were selected and written up was the result of a series of workshops, conference sessions and informal meetings between the editors and the contributing authors. The underlying rationale of the issue together with a core set of guiding questions for contributors to reflect on in their case studies were discussed by the editors at a workshop at the Stockholm Resilience Centre in April 2016. During the 2-day workshop, the editors used a brainstorming and clustering approach to develop the questions that they thought were most important for the case studies to answer, focussing in particular on the design element of the transformative space. Later, these questions were then grouped into a set of five stages in the process of designing transformative spaces (Table 2).

A second author workshop was hosted by the Centre for Complex Systems in Transition under the GRAID programme in South Africa in early December 2016. This 2-day intensive workshop brought together all lead authors of the case study papers, some additional authors and the editors. Based on the framework outlined in Table 2, initial learnings and reflections from the case studies were discussed to refine the questions and to reveal emerging insights from the combination of cases and to see whether the five phases were appropriate for each of the cases. The contributors were able to use the guiding questions to think about their case studies and identify the main aspect that they wanted to emphasise in their article.

The third workshop was held as a special session during the Resilience 2017 conference in Stockholm, Sweden in August 2017. By the time of the conference, first drafts of the papers had been circulated and peer reviewed by other 
contributing authors. The presentations at the conference were aimed at providing key insights from the case studies to group critical emerging themes. During the session, the contributing authors elucidated and further refined more specific cross-cutting themes that emerged from each of the studies. From this, we used thematic clustering and reflective editing of the special issue to generate additional insights on transformations across the case studies. These form the bulk of the analytical material presented in "Unpacking different phases of transformative spaces". For more information on the methods used in the individual cases, please see the respective papers.

\section{Unpacking different phases of transformative spaces}

As is apparent in Table 3, across this set of cases we explore multiple interpretations of what a transformative space actually is and how that translates into practice. We explore a variety of settings and scales: from a small village, to a city municipality through to international organisations. We use the five phases outlined in Table 2 as starting points to identify more generalizable patterns and processes that shape transformative space-making in practice and can also guide the future research of such spaces. The phases we identified are modular and iterative, which is fundamental to ensure a more experimental approach in co-producing impact in social-ecological systems (Fig. 1).

Table 3 presents a full overview of the nine cases, their contexts and design phases. Key insights from each of the phases, with reference to the case studies, are presented in the following sections, followed by concluding remarks on future work on transformative spaces.

\section{Problem definition phase}

In this phase, the transformative space opens questions on scope and the need for new understandings of existing, persistent problems. In a transformative space, opportunities to reframe problems are essential given contexts where populations have inequitable access to information, feel their voices are not heard, and where some forms of knowledge are heavily weighted in comparison to others (Dyer 2018). The convenors of the transformative space, whether a research team or differently configured group, consider design questions such as: What are the goals of the project? What is the problem to be addressed and by whom? Why is it a problem and for whom? With these guiding questions, the design thinking of this phase requires knowledge on the historicity of the problem, the drivers and barriers for resolving the problem and the evidence of maladaptive or unsustainable system states. There is a need from the start to establish that there may be multiple perspectives on understanding why and how the system in question is "locked-in" to the problems, or in a potentially intransient state (Carpenter et al. 2019).

Across the nine cases, most common was an iterative problem definition approach: while the research teams defined a broader problem setting- driven by a project or research discipline- this was followed by inviting local coconveners or their participants to refine this problem statement. In many cases this phase was intimately tied to the second phase, the operationalisation phase, which focused on the selection of participants and partnering with suitable co-convenors. The Xochimilco Wetland case took a different approach by not imposing any broad frame. Instead, they allowed the workshop's problem scope to emerge based on the concerns of participants. While a focus on the urbanization of wetlands was expected, participants instead saw a growing lack of self-esteem and social cohesion as a major issue. In contrast, the Transdisciplinary Research case, developed an approach based on building the legitimacy of knowledge developed through the lived experiences of environmental health challenges. Based on exploratory research, the research team first unpacked marginalised voices and views that were critical to co-creating solutions and defined the problem accordingly. They thus aimed to break through dominant political dynamics that otherwise would have strongly influenced the problem setting.

Various approaches for defining the actual systemic problem, with a varying extent of influence of local actors, can be utilised in the making of a transformative space. As shown across the nine cases, this depends entirely on the context and dynamics between stakeholders. Processes of problem setting inevitably invoke conflict and emotions about understandings of the problem and its impacts on present and future generations. Therefore, conveners must attempt to understand the human dimensions of social-ecological experimentations and recognise the emotions, perceptions and conflicts that are often ignored or understudied in such research. Based on this heightened awareness, an appropriate approach to defining a problem can be selected.

\section{Operationalisation phase}

Issues of diversity (in terms of sectors, perspectives, genders and so on) and processes of inclusion must be considered during the operationalisation phase. Co-production processes inevitably include a process of decision-making whereby conveners select those who will be invited to the space. Ideally, convenors attempt to select and mobilize a representative group of actors, while balancing power dynamics that might exist among actors. However, this selection process, regardless of the intentions, comes with its 


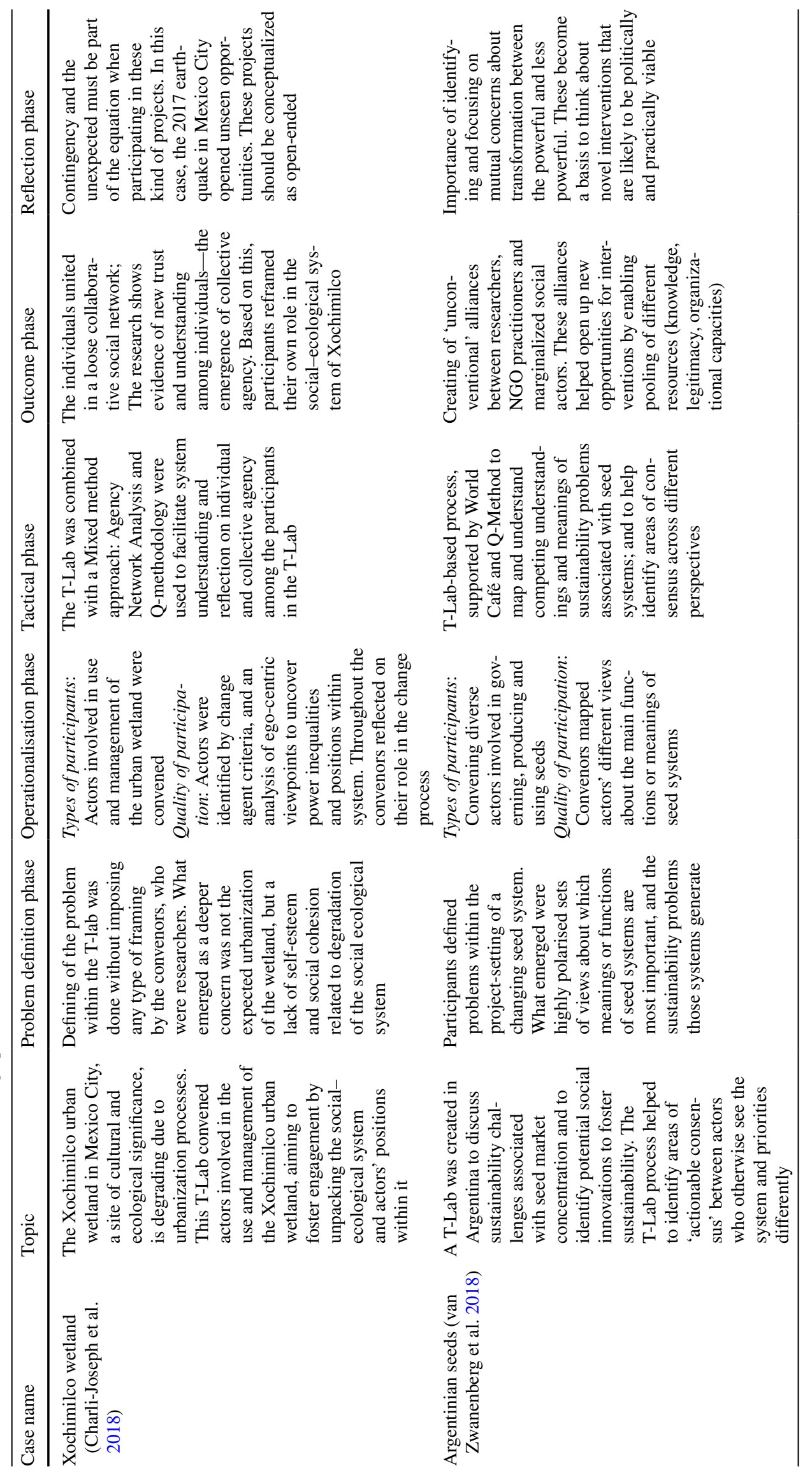




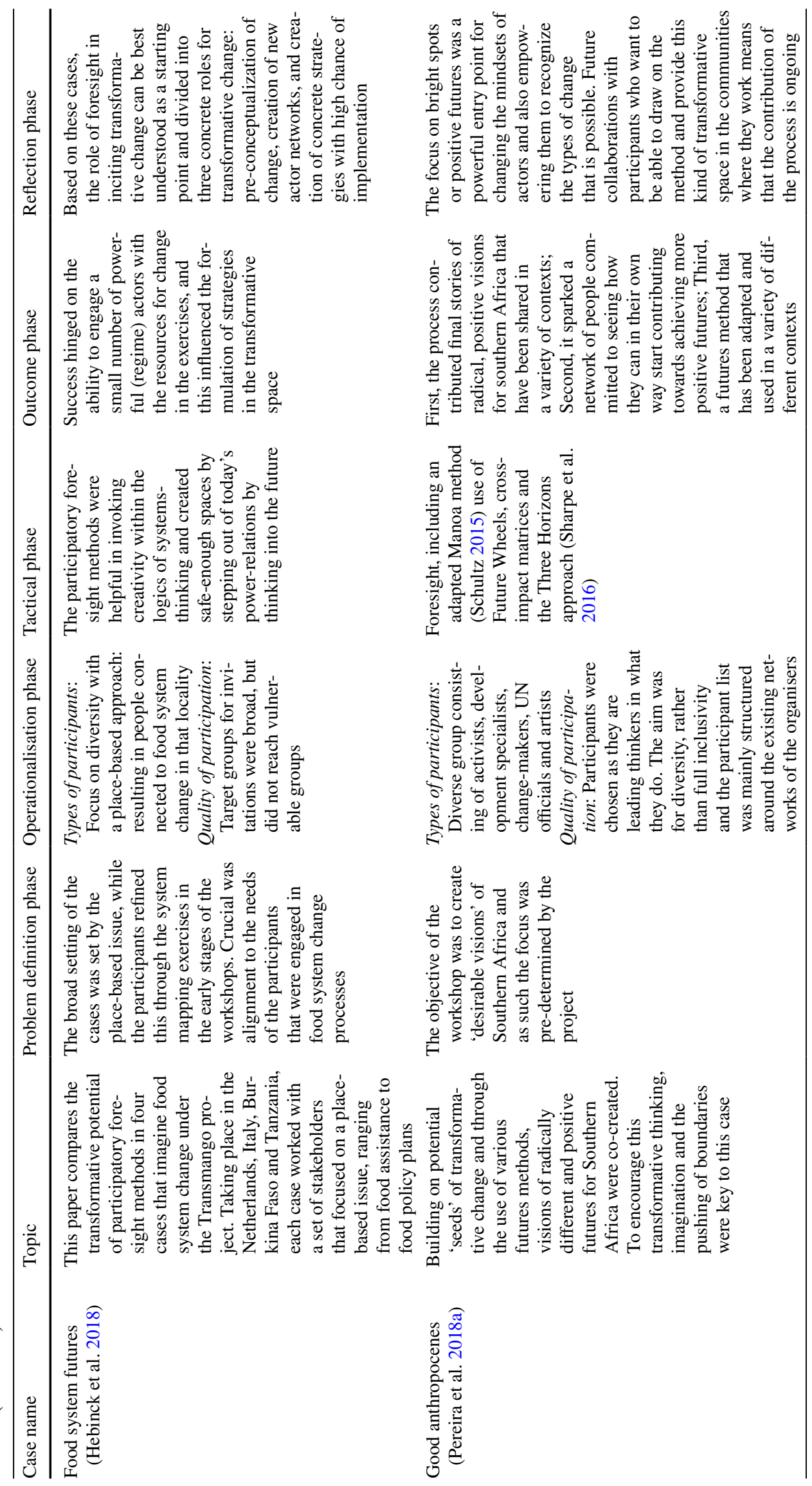




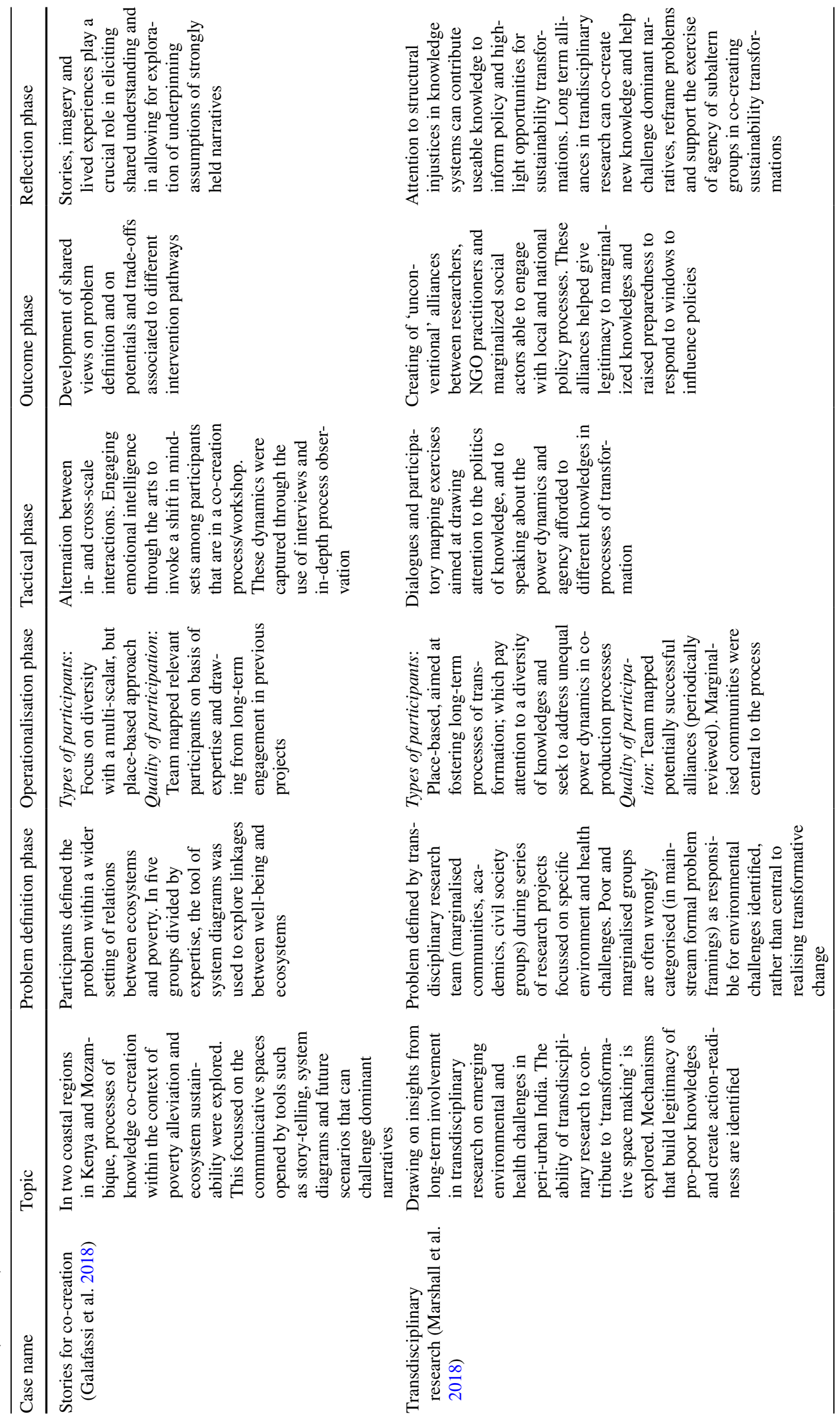




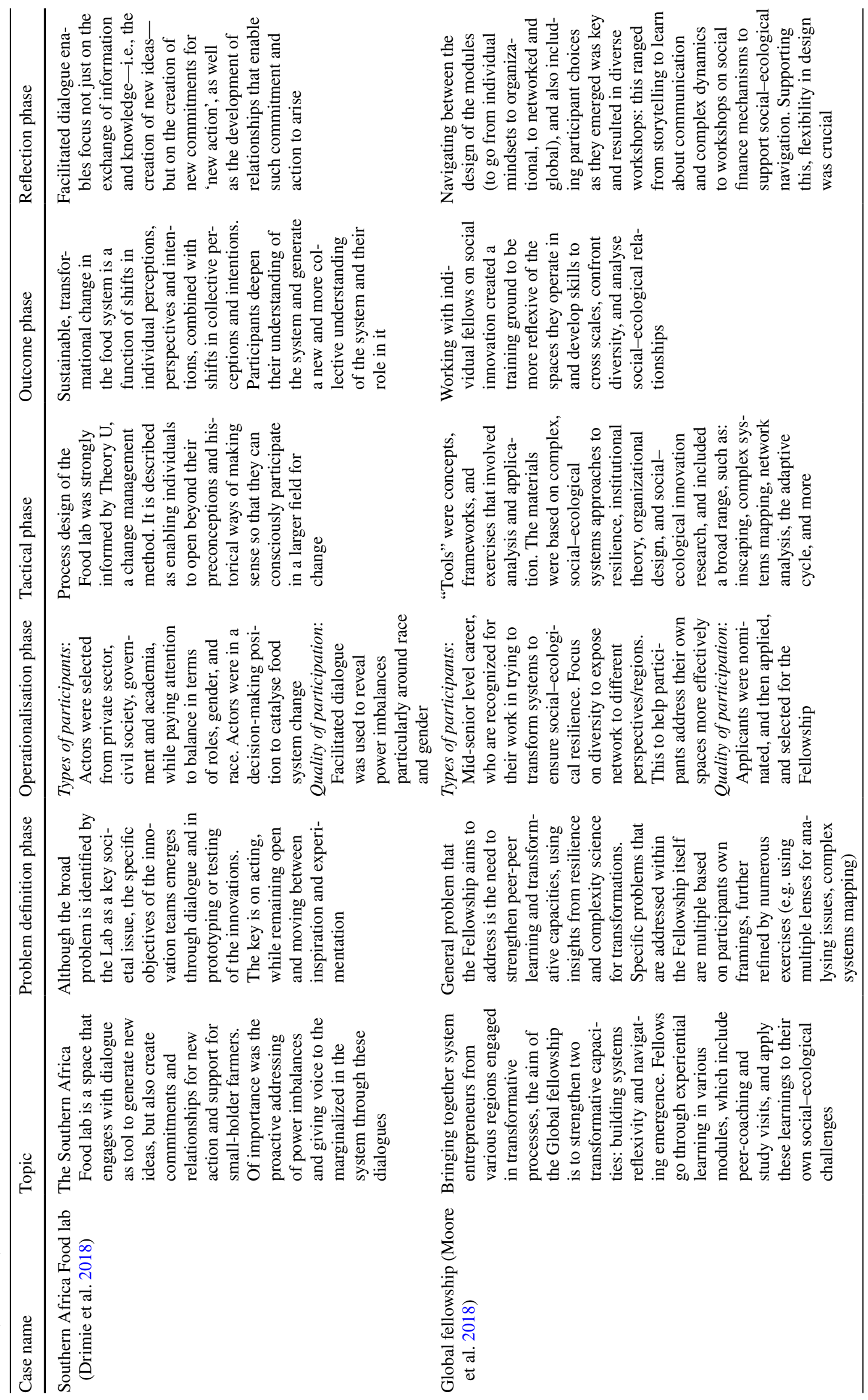




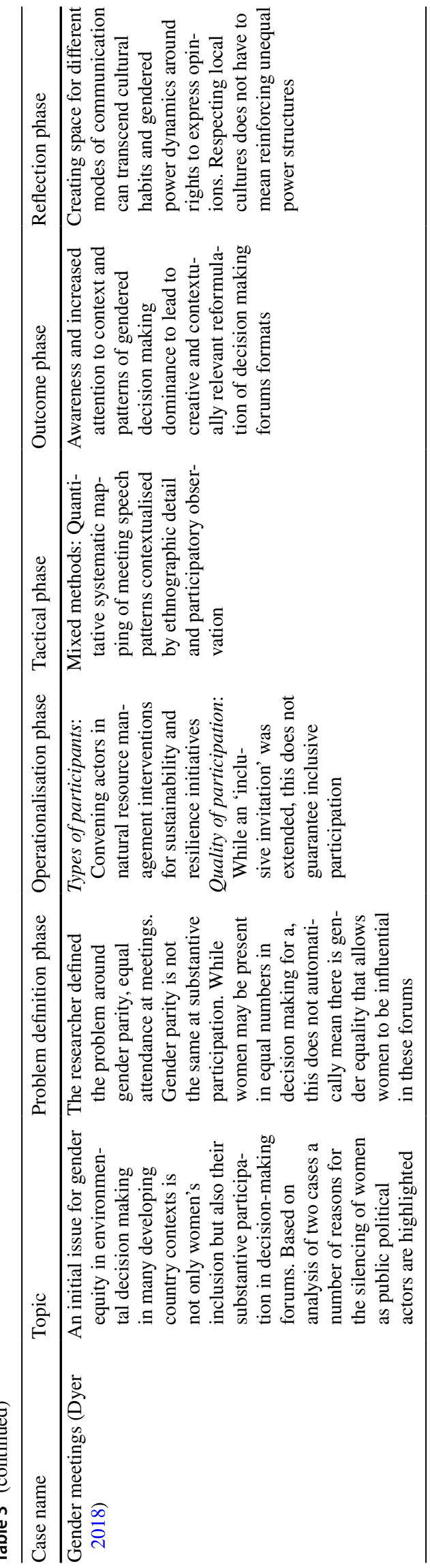

own dimensions of power and consequence. Not only does this impact the subsequent process, but it also demonstrates the inevitable asymmetries that surface in the co-production process (Cornwall 2008). Even when no explicit selection of participants appears to take place, underlying social power dynamics result in a pre-selection of some at the expense of others (Dyer 2018). It becomes crucial for conveners to get a balance in 'types of participants' and 'quality of participation' (Hebinck and Page 2017) amidst these sometimes hidden social dynamics. ${ }^{1}$ Also important is who the conveners themselves are. Although there are real challenges for convenors that are not directly within the system themselves, "outsider" status of conveners can sometimes be advantageous as the participation of "insiders" in shaping the participants of the process might encourage or even discourage participation of certain actors.

Given the majority of the nine cases focused on placebased problems, their operationalisation phase entailed the selection and mobilisation of place-based actors. Along with local co-conveners, research teams mapped out and invited suitable actors that were in various ways connected to the issue at stake while attempting to maintain diversity and look beyond power-structures. In the Southern African Food Lab special attention was given to the selection of participants, as the main selection criteria was a leadership role in their sector (Drimie et al. 2018). This was essential for their aim to instigate new actions and creation of commitments to support smallholder farmers in ensuring community food security within a historical legacy of land dispossessions and concentrated poverty. In their selection of actors from across private sector, civil society, government and academia, their focus was on the participants' ability to ensure representation across sectors and influence on and experience with the system. As such, power dynamics, of actors over the system and of entrenched power inequities, were a major consideration in the operationalisation of this case. In contrast, the aims and objectives of the Global Fellowship case led to a selection approach that focused on diversity that was not explicitly focused on one place, although participants worked on place-based issues. Seeking to strengthen system entrepreneurship, the convenors recognized that systems change requires that agency is distributed across a networked set of actors. To support systems rather than individual entrepreneurship, and to strengthen transformative capacities in a learning space, the design focused on a diverse group of fellows, connected to different networks, embedded in different regions and systems, and with different perspectives.

\footnotetext{
1 As emphasised in "Problem definition phase", the ability of conveners to get a good representation is partly influenced by the problem definition, sometimes leading to the choice to give participants space to reframe problems.
} 
Fig. 1 Five phases for the design of transformative spaces that iteratively feed into each other and are dynamic into the future (i.e., there is no determined end-point)

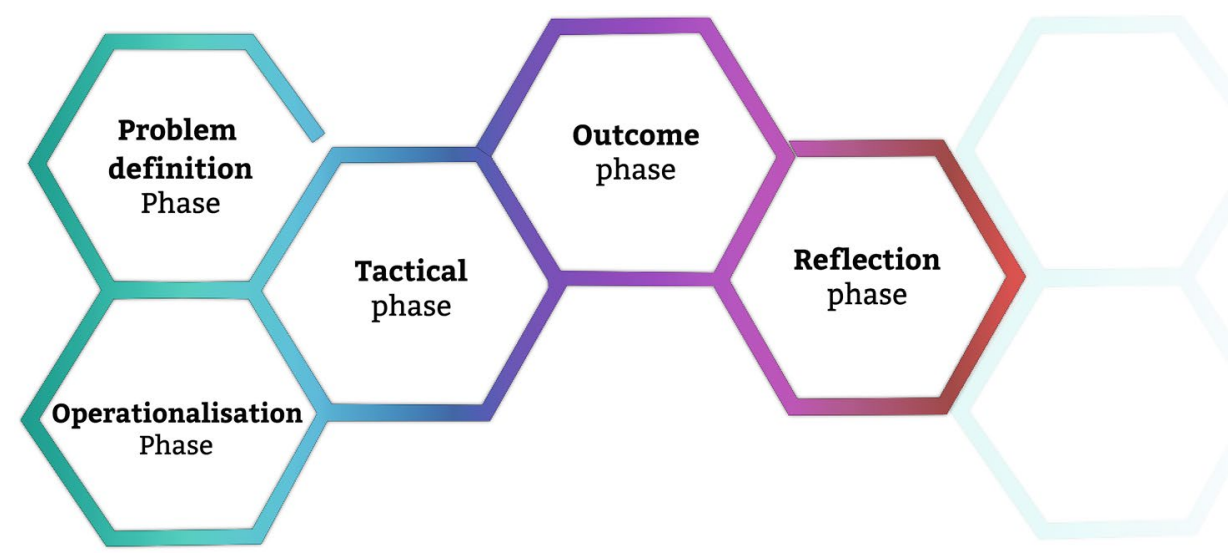

This creates certain power asymmetries as every participant is confronted with a diversity of views about transformations in their environment.

Even with careful selection processes that pay attention to these complex social dynamics, some form of power will inevitably enter into the convened space, including potential conflicts arising from pre-existing tensions or prejudices. Likewise, it is critical to acknowledge that transformative spaces do not occur in a vacuum, and participants have a history of engagement with other convened processes and may possibly feel some form of research or engagement fatigue (see Lemos et al. 2018). Knowing such dynamics can affect the 'quality of participation' during a process, given that these can affect the quality of a 'safe space' for certain actors (Gaventa and Cornwall 2008). Lessons learned from these cases demonstrate that such sensitivities can be mediated to some extent through the choice of methods (see next section). Open reflexivity and transparency in terms of selection is vital to convening a transformative space. Over time, who is included in the transformative space may also shift and this reflexivity is important to be able to ensure that the space allows for this fluidity as interests change.

\section{The tactical phase: the methods and toolbox for transformative spaces}

The tactical phase is focused on the choice, development and application of methodologies to enable a transformative space, and to support the work that will be done in that space, by the conveners, independently or together with participants. In most cases, conveners decided upon developing a toolbox: a range of facilitation and data collection methods that work towards meeting the objective of the transformative space and scientifically record the process. The choice of facilitation tools depends on the earlier phases of problem defining and operationalisation since certain methods are aimed towards understanding the current system, while others focus on working towards catalysing system change, and some on both. The social innovation lab guide (Westley and Laban 2012), outlines one way through which to ensure that different tools are used in certain sequences so as to increase the likelihood that the goals and outcomes are achieved at each stage of the process. Since there is no perfect approach, and always many optional pathways to undertake these kinds of processes, choosing the "right" tools for each group can be a tricky process, and it is also important to recognise when a particular method is not working with a group and to shift to something else (Zgambo 2018).

The conveners employed different types of participatory methodologies, such as participant observation, narrative enquiry, participatory scenario mapping and participatory impact pathways analysis. In some spaces, mixed quantitative-qualitative approaches were used to facilitate system understanding, such as Agency Network Analysis and Q-Methodology (Table 3). The case Stories for co-creation applied an approach that engaged actively and purposefully with the emotional intelligence of participants through the use of arts. Here, the application of performative arts and its ability to contribute to opening up different perspectives to the transformations needed to tackle climate change was explored. The case shows how the use of artistic interventions allowed for a move from a mere cognitive understanding of facts to a process of revealing perceptions and underlying worldviews that mediated that understanding. The research team captured these shifts of perceptions and mind-sets through narratives, interviews and, in-depth process observation.

Creativity was used in the case of Food System Futures as a way to think about what a desired food system could look like. Through the use of participatory foresight methods, participants were encouraged to think imaginatively while within the bounds of system-logics, resulting in four plausible future food systems. In this case, the use of system thinking contributed to increased understanding of the food system, the different actors and their activities, and (un)desired 
system outcomes. By combining this system-understanding with a futures lens, participants were able to step out of the today's dominant power-structures and challenge currently dominant trade-offs. Moreover, the research team took an iterative approach to this tactical phase, allowing for swift adjustment in case the process took an unexpected turn or did not meet objectives.

As the cases highlight, while the methods themselves may not be unique and could be used in other types of processes, it is the choice of methods for designing and facilitating work within the space that is crucial for the establishment of a transformative space. It is thus critical to match the methods and tools employed in the process with the key outcomes that it seeks to achieve and ensure that they are meaningful to the contextual dynamics. The combination of methods (see Table 3) gives structure to the participants and to the facilitation of the transformative space, and is tailored to the contexts in which the transformative spaces are embedded. In this way, the transformative space can start to model (and even exemplify) different ways of working, which may be essential to the future transformative efforts in this space.

\section{Outcomes phase: understanding and measuring impacts for transformative change}

In this phase, the authors work towards understanding what the key outcomes for transformative change are. It takes stock of the impacts of the transformative space at the individual, the collective and system level and reflects on the efforts of researchers to track and understand changes that emerge. Detecting change that can be attributed directly to the transformative space is challenging, particularly in relation to a 'live' and open process, where there are multiple influencing processes and events outside the domain of the transformative space. While some notable changes may occur during or immediately following the implementation of an experimental process, other changes may emerge later-possibly associated with individual change and relationships initiated during the transformative space.

The difficulty with trying to identify, undertake and assess transformative change can be identified across the cases, as most conclude that the transformative spaces are actually starting points of change, rather than endpoints (see Fig. 1 for a visual representation). Instead, the cases give insights into how change has been effected at individual, collective and system levels and how these change processes might be further catalysed. In the Argentinian Seeds case, a key outcome of the transformative space was the creation of 'unconventional' alliances between researchers, NGO practitioners and social actors that are systematically marginalised within formal policy dialogues, such as around agricultural seed markets. Through the creation of novel alliances of actors, the transformative space helped to open up new opportunities for intervention. These new alliances enabled a pooling of different kinds of resources, such as of knowledge, legitimacy and organizational capacity, to help overcome some of the difficulties of trying to galvanise action for building more sustainable pathways of change in the context of pervasive 'locked-in' agricultural systems.

Echoing through the cases is the contribution of transformative spaces in the development of connections between actors that are normally fragmented and how their improved understanding of system dynamics can be catalytic to effecting larger change and help to re-organise these systems. To analyse and track progress towards more systemic change as an outcome of transformative spaces, research teams need to be more creative and reflexive about monitoring and evaluation. While this is often overlooked, it could contribute to the identification of both qualitative and even quantitative signs of change. More work to be able to track the real impact of these spaces, the reconfigured relationships and changes in mind-sets is critical for furthering the work on understanding and instigating transformative change (see O'Brien and Synga 2013 with reference to responding to climate change).

\section{Reflection phase}

Concluding the design phases, reflection is important to explore and understand what worked and what did not. Reflecting includes debriefing on whether expectations aligned, objectives were met, and how power-dynamics in the space enabled or disabled transformative change. Powerful actors that command resources and influence can often pose an important barrier to change. These issues mean that a transformative space is often not a transformation in itself, but rather a form of preparedness for transformation that entails unlocking constructive ways of working with power dynamics that are undeniably constitutive of any social-ecological system (Moore et al. 2018). In transformations, a single intervention is insufficient as the system has been locked into unsustainable and unjust trajectories due to historical path dependencies and requires a much longer-term engagement. Moreover, the larger the scale of transformation desired; the longer the time required to observe impact and change. For these larger higher-level transformative changes, new methods and longer time commitments are needed.

Transformative spaces must be crafted so as to allow for conflict to be a productive process of contestation, of unmasking interests and rethinking perceptions. In this way, these spaces move away from the consensus model (Mostert 2015) that informs many efforts at transdisciplinary engagement. Consequently, they can facilitate the development of social interactions between actors that 
previously did not come into dialogue. In the Gendered Meetings case, the ethnographic approach used to understand underlying gendered dynamics of communication in Solomon Islands villages revealed that prima facie assessments of participation can be misleading. It concludes that without recognition of how some communicative practices gain dominance, and thus voice, over others, real transformation is unlikely to take place. This is one way that transformative spaces are distinct from other experimental settings and participatory processes, as they are deliberate in inviting conversations about conflict and its causes and are thereby open to the human dimensions of deliberations about future pathways. The Good Anthropocenes case shows how transformative spaces allow for a shift in personal perspectives in terms of reframing and re-thinking initially negative images (the Anthropocene) by explicating positive changes and enriching the dialogue with transformative visions. This case shows how alternative approaches can be a useful approach to foster dynamics of change. In this instance, a focus on positive futures allowed participants better to link current practices to transformative change, contributing a set of approaches that enabled societal actors to deal with changes needed for transformation and to see their individual contributions to the larger vision.

The other cases also illustrated ways of doing this reflecting, such as identifying and focusing on mutual concerns between both powerful and less powerful players, and to use these as a basis to think about ways forward. Critical to developing transformative spaces is a serious and open engagement with how knowledge is being created and utilised, not just in terms of bringing diverse actors together to co-produce new knowledge in a particular setting, but with a mutual recognition that context, culture and power will shape the form of understandings of all involved (Stirling and Mitchell 2018). Another implication is how this understanding plays out in wider knowledge systems with the structural injustices that they encompass (Marshall et al. 2018). As such, transformative spaces have the potential to transform the value of knowledge, heightening it to a common resource and public good rather than a power tool for the selected or privileged few.

Researchers are key actors in transformative spaces and as a result can do a great deal in helping to turn power from a disabler into an enabler for transformation. However, they are also bound by their own rhythms of work and institutional commitments. In retrospect, this can pose barriers towards realising their full potential as transformative space-makers (Hebinck et al. 2018; Marshall et al. 2018). The limited time available in projects and the results-driven frameworks sometimes mean that they have less time to spend in the transformative space or cannot meet expanding and ongoing expectations. In turn, this may limit the information and knowledge researchers gain on the multiple outcomes of these spaces, creating in this way a knowledge gap. This is particularly true in the Global South were structural injustices may be more pervasive.

\section{Key lessons relating to research in transformative spaces}

The aim of this synthesis has been to explore how to create spaces for developing initiatives and approaches that can contribute to large-scale, systemic transformations that strengthen the relationship between people and planet. Central to this goal is the pressing need to make transformation more directly relevant to the conditions that arise in the Global South. This includes addressing marginalisation; dealing with and confronting the long legacies of colonialism in its many manifestations, and whose effects are still experienced; and challenging the status quo to help address social and power inequalities. Indeed, these are issues that have not had a central place in SES transformation research, but are arguably central to any social-ecological change process, and are particularly salient to the conditions of transformation.

We conclude that transformative spaces, through designing the engagement and dialogues in ways that involve and consider emotions and allowing for empathy, further contribute to humanizing the solutions. We argue this is a distinguishing feature of the co-created outcomes of transformative spaces, that they are immediately socially relevant, and neither impersonal, nor apolitical. We consider researchers such as ourselves not just to be distant observers of transformation, but in fact to have considerable agency in catalysing or creating conditions for transformation (Milkoreit et al. 2015). In other words, we can help create or support the seeds for transformation when these seeds are weak or completely lacking. Researchers are not just knowledge makers or more conservatively, knowledge holders (a dominating paradigm in Western knowledge systems), but transformation makers and facilitators, and hence consciously or not, they are changing their own roles, identities and values in the process. There is much to be gained from ensuring that the learnings from transformative spaces are as diverse as possible and are not restricted to Western paradigms and problem-framings. Transformative spaces allow for a reflection on the broadening and shifting roles of researchers in both North and South research communities. Another insight has been that creating transformative spaces is not about a single event or workshop. Rather it is a continued process of engagement through designed 
and facilitated interactions that often involve a series of workshops or programs that requires planning, organisation and curation.

Opening up to emphasise the vital knowledge and capacities for enabling transformative change that are prevalent in the Global South is a crucial research gap. This paper has made a first attempt to synthesise some of the many learnings that a cross-case comparison can elucidate, whilst holding true to the individuality of the studies and recognising that these findings are not universal. Below we identify five key findings from the nine cases.

\section{Ethical dilemmas associated with creating a transformative space in a system}

First, all the cases raise some ethical dilemmas when creating a transformative space, whether initiated by a researcher, an NGO or a grassroots organization. Transformative spaces often initially start small, and so almost by definition, they are exclusive rather than inclusive spaces. While they do not have to be organized as small "closed" spaces, the nature of the interpersonal interactions and engagement that these processes are designed to foster supports a more intimate design. Transformative spaces are designed to generate ideas that challenge the status quo and the dominant systems, and hence change the systems conditions that created the problems in the first place. This means that a transformative space can put participants at risk because the ideas can be seen as controversial to others who can feel threatened by the new ideas, especially if the ideas change power relations. For some participants, engaging with such ideas could entail exclusion from their communities or in some cases, a fear for their own life (see Drimie et al. 2018). As Moore et al. (2018) highlight, transformative spaces can indeed "feeland be-dangerous" because they challenge stability and predictability. However, such efforts to give voice to the powerless may also give rise to internal resistance to change, and possible setbacks, as actors in the system become nervous when power imbalances are explicitly identified and addressed. Power-related tensions arose amongst intended beneficiaries of the agro-ecology leadership program in the Food Lab case study, when some smallholders worried about a course participant becoming too dominant due to newfound knowledge and confidence. Especially in the Global South, where these issues of vulnerability and marginalisation are often explicit, the ethical implications of engaging in the system need to be acknowledged by researchers upfront. This includes being honest about setting expectations about the outcome of the process. It is only by further investigating processes in these contexts that a better understanding of these ethical dilemmas and ways to ensure the wellbeing of all participants can be developed and that expectations of change can be better managed.

\section{Readiness of the system for change}

Second, related to the previous point is the importance to assess the readiness of the system for change and avoid initiating change processes too early, with a higher risk of failure because the convenors (and possibly the participants) do not understand the system. Understanding the readiness of the system for change will allow transformative spaces' outcomes to be more easily adopted or even institutionally embedded outside the group of participants in the transformative space (Westley et al. 2017). Even when there are small 'openings for change' there are signals that communities of practice and research should not neglect nor hesitate to seize. We need to keep in mind that it is not only the experimentation process itself, but part of the open-endedness of experimentation that makes it critical to identify the individuals, organizations, and networks that are deeply committed to changing the dynamics of systems that they themselves may represent. It is necessary to include a diverse range of relevant actors who develop a shared sense of ownership of the process for it to be sustained in the long-term and to effect change at the 'systems' level. It is also important to have a baseline from which to assess potential changes in the system.

\section{'Safe' vs. 'safe-enough' spaces for transformation}

Third, the cases raise the issue of transformative spaces as "safe" or "safe-enough". One aspect of this is that the participants might be putting themselves at risk by participating. But the "safe" also means that transformative change requires learning, and more specifically "un and re-learning" in order for participants to challenge their own thinking, and let go of preconceived ideas (Olsson et al. 2017). This often means that participants show personal vulnerability. The Global Fellowship, T-labs and the Food lab were all designed for "unlearning"; they challenge preconceived ways of thinking and knowing, and use different methods to guide the participants through such processes. The idea is that to transform a system, it is necessary to undergo changes at the personal level (including scientists' assumptions) and then to start building capacities and networks for change. This implies that there is a need for a level of discomfort to be able to process internal transformations and act systemically. As well as personal learning, the encounter with diverse opinions can also be an uncomfortable space for some participants, especially if they disagree with what is being said. Creating an environment where all feel safe enough to articulate their differences can be vital in some instances. 


\section{Assemblage of frameworks for transdisciplinary research}

Fourth, transformative spaces require an assemblage of frameworks to set up the transdisciplinary research; simply put, there is 'no one size fits all' situation. The cases show that a diversity of methods, tools and skills is required for transformative spaces to be designed, operated and reflected upon. Similar reflections have emerged from literature on living labs as spaces for intervening around sustainability in cities (Voytenko et al. 2016; Bulkeley et al. 2016). Next to this, tools and methods are not neutral, but are necessarily constructed on particular assumptions and perspectives on knowledge, which in turn can shape outcomes dramatically. It is therefore important for researchers to reflect on these assumptions so as to design processes that fit the contextual dynamics at play and the interests of those involved. It is also important to avoid matching or mixing frameworks and theories that come from ontologically opposing sides because such a mis-match will generate non-reliable findings (that in turn will deteriorate the eligibility and reliability of process outcomes). This comes together with the researcher's willingness to reflect on their own role and be willing to question their own assumptions.

\section{Transformative spaces as starting points for institutionalising change}

Fifth, transformative spaces as unique knowledge-action interfaces can either foster a transformation from infancy or institutionalise ongoing transformative processes by creating, strengthening and even 'positioning' new social networks. As transdisciplinarity becomes normalised within research, there is a need to recognise the different practices within this larger epistemological framing of which the growing scholarship around transformative spaces is an example. A transformative space is a form of preparedness for transformation, unlocking constructive ways of working with power dynamics in the status quo. As such, transformative spaces allow participants, including the conveners or researchers involved, to reflect on their individual agency, their capacities and perspectives that enable or disable collective action, the forms of alliances they can build, and new ways of seeing their world that open up alternative pathways forward. Because transformative spaces operate within ongoing, highly complex and often contested social-ecological realities, it is possible that these spaces provide participants with the space for reflection that then empowers them to mobilize change in other arenas. This echoes what Lotz-Sisitka et al. (2015) refer to as the need to develop transgressive learning or disruptive capacity building that moves beyond existing notions of adaptive management. Transformative spaces can provide the contexts for institutionalising these kinds of more radical system interventions.

\section{Conclusions}

This article synthesises the learnings from research engagements across nine diverse cases in transformative spaces in a development context, which were individually set out in a Special Issue in Ecology and Society (see Pereira et al. 2018b). This synthesis paper provides concrete insights for the crafting of fitting methodologies to research transformative spaces in a development context. We do so by setting the cases out in the five phases that we argue can be recognised in transformative spaces. This process allowed us to distil a number of key messages that should be considered when designing transformations-oriented research. We urge anyone engaging in or designing research in transformative spaces to stay mindful of these five points:

- There are ethical dilemmas associated with creating a transformative space in a system;

- It is important to assess the readiness of the system for change before engaging in it;

- There is a need to balance between 'safe' and 'safeenough' spaces for transformation;

- Convening a transformative space requires an assemblage of diverse methodological frameworks and tools;

- Transformative spaces can act as a starting point for institutionalising transformative change.

In addition, by choosing case studies from the Global South, we have tried to highlight how learning from these perspectives can disrupt Western ideas about transformation and push transformation research and practice into new directions. Such emphasis includes a stronger focus on dimensions of justice, history, power and contested meaning. Galvanising the initial learnings about transformative spaces from the Global South has global significance, as much research on transformations so far has been typically set out to address problems and challenges in the Global North, or 'Western' contexts. The need to ensure that theories on transformation are not based solely on research from privileged regions of the world is an imperative if the world is to move onto a more sustainable pathway. As such, the paper addresses the broader picture of transformation across diverse contexts and yields insights with implications across the North-South continuum.

Our approach to transformative spaces recognises that disrupting the dominance of Western examples is a key stepping stone for accelerating global transformations for two reasons. First: there is no transformation without challenging 
the status quo in each of its various manifestations. In the Global South, there is historically less trust of the status quo and hence a window of opportunity to experiment with transformation from a different vantage point. Second, by turning to the Global South we attempt to challenge the deep institutionalisation of Western-based knowledge paradigms. The transformative space is essentially a way to bring the agency and knowledge of those actors that are typically left behind by these paradigms. This relates to the ethical dilemmas of transformation and efforts to deal with them in the knowledge co-production process.

Many researchers are now engaging in transformations research as transformative space-makers and have moved away from dominant ways of researching change as observers, but there is a continued need to expand our understanding and exploration of how these transformative spaces play out in the long term. As Fazey et al. (2018: 54) note in the context of climate research, researchers need to acknowledge that they work from within the system and become reflexive to taking on alternative roles that are more experimental and action-oriented, to deliver more "highly adaptive, reflexive, collaborative and impact-oriented research". Here we have presented tangible examples of research that is doing exactly this in diverse contexts in the Global South. There is need for urgent action towards more sustainable and just futures for people and the planet and there is a pivotal role that research can play in catalysing this change. We hope that by sharing our experiences from across different geographies that we have been able to ignite continued scholarship, which will be able to contribute to the urgent global transformation to a more equitable and sustainable planet Earth.

Acknowledgements Open access funding provided by Stockholm University. We are thankful to all contributors of the special feature, for sharing their insight knowledge to further improve and enrich the conceptualization of transformative spaces, for dedicating their time in a series of workshops, for their participation in the Resilience Conference 2017 in Stockholm, Sweden and above all for their dedication in transformative, transdisciplinary research. Drs. Pereira, Moore, and Olsson would like to acknowledge the contribution of the SIDA-funded GRAID (Guidance for Resilience in the Anthropocene: Investments for Development) project for funding their contribution to the programme, as well as the workshop hosted in Cape Town in 2016. Part of this research was conducted under the TRANSMANGO project, granted by the EU under 7th Framework Program, theme KBBE.2013.2.5-01 (Assessment of the impact of global drivers of change on Europe's food security), Grant agreement no. 613532. This work is also partly based on a research project supported by the Transformations to Sustainability Programme, which is coordinated by the International Science Council (ISC), funded by the Swedish International Development Cooperation Agency (Sida), and implemented in partnership with the National Research Foundation of South Africa.

Open Access This article is distributed under the terms of the Creative Commons Attribution 4.0 International License (http://creativeco mmons.org/licenses/by/4.0/), which permits unrestricted use, distribution, and reproduction in any medium, provided you give appropriate credit to the original author(s) and the source, provide a link to the Creative Commons license, and indicate if changes were made.

\section{References}

Börzel TA, Risse T (2010) Governance without a state: can it work? Regul Gov 4:113-134. https://doi.org/10.111 1/j.1748-5991.2010.01076.x

Bosch OJH, Nguyen NC, Maeno T, Yasui T (2013) Managing complex issues through evolutionary learning laboratories. Syst Res Behav Sci 30:116-135. https://doi.org/10.1002/sres.2171

Brondizio ES, O'Brien K, Bai X et al (2016) Re-conceptualizing the Anthropocene: a call for collaboration. Glob Environ Change. https://doi.org/10.1016/j.gloenvcha.2016.02.006

Bulkeley H, Coenen L, Hartmann C et al (2016) Urban living labs: governing urban sustainability transitions. Curr Opin Environ Sustain 22:13-17. https://doi.org/10.1016/j.cosust.2017.02.003

Carpenter SR, Folke C, Scheffer M, Westley FR (2019) Dancing on the volcano: social exploration in times of discontent. Ecol Soc. https ://doi.org/10.5751/es-10839-240123

Charli-Joseph L, Siqueiros-Garcia JM, Eakin H et al (2018) Promoting agency for social-ecological transformation: a transformation-lab in the Xochimilco social-ecological system. Ecol Soc. https://doi. org/10.5751/es-10214-230246

Cornwall A (2008) Unpacking "Participation": models, meanings and practices. Community Dev J 43:269-283. https://doi.org/10.1093/ cdj/bsn010

Díaz S, Demissew S, Carabias JJ et al (2015) The IPBES conceptual framework-connecting nature and people. Curr Opin Environ Sustain 14:1-16

Dinnen S, Firth S (2008) Politics and state building in Solomon Islands. Australian National University Press, Canberra

Drimie S, Hamann R, Manderson AP, Mlondobozi N (2018) Creating transformative spaces for dialogue and action: reflecting on the experience of the Southern Africa Food Lab. Ecol Soc. https:// doi.org/10.5751/es-10177-230302

Dyer M (2018) Transforming communicative spaces: the rhythm of gender in meetings in rural Solomon Islands. Ecol Soc. https:// doi.org/10.5751/es-09866-230117

Fazey I, Schäpke N, Caniglia G et al (2018) Ten essentials for actionoriented and second order energy transitions, transformations and climate change research. Energy Res Soc Sci 40:54-70. https:// doi.org/10.1016/j.erss.2017.11.026

Frantzeskaki N, Wittmayer J, Loorbach D (2014) The role of partnerships in "realizing" urban sustainability in Rotterdam's City Ports Area, the Netherlands. J Clean Prod 65:406-417

Galafassi D, Daw TM, Thyresson M et al (2018) Stories in social-ecological knowledge cocreation. Ecol Soc. https://doi.org/10.5751/ es-09932-230123

Gaventa J, Cornwall A (2008) Power and Knowledge. In: Reason P, Bradbury H (eds) The SAGE handbook of action research: participative inquiry and practice, 2nd edn. SAGE Publications, London

Hebinck A, Page D (2017) Processes of participation in the development of urban food strategies: a comparative assessment of exeter and eindhoven. Sustainability 9:931. https://doi.org/10.3390/ su9060931

Hebinck A, Vervoort JM, Hebinck P et al (2018) Imagining transformative futures: participatory foresight for food systems change. Ecol Soc. https://doi.org/10.5751/es-10054-230216

Hickel J (2012) Neoliberal plague: the political economy of HIV transmission in Swaziland. J S Afr Stud 38:513-529. https://doi. org/10.1080/03057070.2012.699700 
Hickel J (2016) The true extent of global poverty and hunger: questioning the good news narrative of the Millennium Development Goals. Third World Q 37:749-767. https://doi.org/10.1080/01436 597.2015.1109439

Lemos MC, Arnott JC, Ardoin NM et al (2018) To co-produce or not to co-produce. Nat Sustain 1:722-724. https://doi.org/10.1038/ s41893-018-0191-0

Lotz-Sisitka H, Wals AEJ, Kronlid D, McGarry D (2015) Transformative, transgressive social learning: rethinking higher education pedagogy in times of systemic global dysfunction. Curr Opin Environ Sustain 16:73-80. https://doi.org/10.1016/j.cosus t.2015.07.018

Luederitz C, Schäpke N, Wiek A et al (2017) Learning through evaluation-a tentative evaluative scheme for sustainability transition experiments. J Clean Prod 169:61-76. https://doi.org/10.1016/j. jclepro.2016.09.005

Marshall F, Dolley J (2019) Transformative innovation in peri-urban Asia. Res Policy 48:983-992. https://doi.org/10.1016/j.respo 1.2018.10.007

Marshall F, Dolley J, Priya R (2018) Transdisciplinary research as transformative space making for sustainability: enhancing propoor transformative agency in periurban contexts. Ecol Soc. https://doi. org/10.5751/es-10249-230308

Mbembe A (2000) At the edge of the world: boundaries, territoriality, and sovereignty in Africa. Public Cult 12:259-284. https://doi. org/10.1215/08992363-12-1-259

Menkhaus K (2007) Governance without government in somalia: spoilers, state building, and the politics of coping. Int Secur 31(3):74-106

Milkoreit M, Moore ML, Schoon M, Meek CL (2015) Resilience scientists as change-makers-Growing the middle ground between science and advocacy? Environ Sci Policy 53:87-95. https://doi. org/10.1016/j.envsci.2014.08.003

Moore M-L, Olsson P, Nilsson W et al (2018) Navigating emergence and system reflexivity as key transformative capacities: experiences from a Global Fellowship program. Ecol Soc. https://doi. org/10.5751/es-10166-230238

Morgan M (2005) Cultures of dominance: institutional and cultural influences on parliamentary politics in Melanesia. Australian National University, Canberra

Mostert E (2015) Who should do what in environmental management? Twelve principles for allocating responsibilities. Environ Sci Policy 45:123-131. https://doi.org/10.1016/j.envsci.2014.10.008

Mukute M, Lotz-Sisitka H (2012) Working with cultural-historical activity theory and critical realism to investigate and expand farmer learning in Southern Africa. Mind Cult Act 19:342-367. https://doi.org/10.1080/10749039.2012.656173

Nagendra H, Bai X, Brondizio ES, Lwasa S (2018) The urban south and the predicament of global sustainability. Nat Sustain 1:341349. https://doi.org/10.1038/s41893-018-0101-5

O’Brien K, Synga L (2013) Responding to climate change: the three spheres of transformation. In: Proceedings of transformation in a changing climate. Oslo, Norway

Olsson P, Moore ML, Westley FR, McCarthy DDP (2017) The concept of the Anthropocene as a game-changer: a new context for social innovation and transformations to sustainability. Ecol Soc. https ://doi.org/10.5751/es-09310-220231

Omeje K (2017) Extractive economies and conflicts in the global south: re-engaging rentier theory and politics. In: Omeje K (ed) Extractive economies and conflicts in the global south. Routledge, Oxford, pp 19-44

Pereira L, Karpouzoglou T, Doshi S, Frantzeskaki N (2015) Organising a safe space for navigating social-ecological transformations to sustainability. Int J Environ Res Public Health 12:6027-6044. https://doi.org/10.3390/ijerph120606027

Pereira LM, Hichert T, Hamann M et al (2018a) Using futures methods to create transformative spaces: visions of a good Anthropocene in southern Africa. Ecol Soc. https://doi.org/10.5751/es-09907 $-230119$

Pereira LM, Karpouzoglou T, Frantzeskaki N, Olsson P (2018b) Designing transformative spaces for sustainability in socialecological systems. Ecol Soc. https://doi.org/10.5751/es-10607 $-230432$

Pohl C, Rist S, Zimmermann A et al (2010) Researchers' roles in knowledge co-production: experience from sustainability research in Kenya, Switzerland, Bolivia and Nepal. Sci Public Policy 37:267-281. https://doi.org/10.3152/030234210x496628

Preiser R, Pereira LM, Biggs R (2017) Navigating alternative framings of human-environment interactions: variations on the theme of 'Finding Nemo'. Anthropocene 20:83-87. https://doi. org/10.1016/j.ancene.2017.10.003

Schäpke N, Stelzer F, Caniglia G et al (2018) Jointly experimenting for transformation? Shaping real-world laboratories by comparing them. GAIA Ecol Perspect Sci Soc 27:85-96. https://doi. org/10.14512/gaia.27.s1.16

Schultz W (2015) Manoa: the future is not binary. APF Compass 22-26

Scoones I, Stirling A, Abrol D et al (2018) Transformations to sustainability. Sussex

Sharpe B, Hodgson A, Leicester G et al (2016) Three horizons: a pathways practice for transformation. Ecol Soc. https://doi. org/10.5751/es-08388-210247

Steffen W, Broadgate W, Deutsch L et al (2015) The trajectory of the Anthropocene: the great acceleration. Anthr Rev 2:1-18. https:// doi.org/10.1177/2053019614564785

Stirling A, Mitchell C (2018) Evaluate power and bias in synthesizing evidence for policy. Nature 561:33. https://doi.org/10.1038/d4158 6-018-06128-3

Tengö M, Brondizio ES, Elmqvist T et al (2014) Connecting diverse knowledge systems for enhanced ecosystem governance: the multiple evidence base approach. Ambio 43:579-591

van Breda J, Swilling M (2019) The guiding logics and principles for designing emergent transdisciplinary research processes: learning experiences and reflections from a transdisciplinary urban case study in Enkanini informal settlement, South Africa. Sustain Sci 14:823-841. https://doi.org/10.1007/s11625-018-0606-x

van Zwanenberg P, Cremaschi A, Obaya M et al (2018) Seeking unconventional alliances and bridging innovations in spaces for transformative change: the seed sector and agricultural sustainability in Argentina. Ecol Soc. https://doi.org/10.5751/es-10033-230311

Voytenko Y, Evans J, Schliwa G (2016) Urban living labs for sustainability and low carbon cities in Europe: towards a research agenda. J Clean Prod 123:45-54. https://doi.org/10.1016/j.jclep ro.2015.08.053

Westley FR, Laban S (2012) Social innovation lab guide. Waterloo, Canda

Westley FR, McGowan K, Tjornbo O (2017) The evolution of social innovation: building resilience through transitions. Edward Elgar, Cheltenham

Wittmayer JM, Schäpke N (2014) Action, research and participation: roles of researchers in sustainability transitions. Sustain Sci 9:483-496. https://doi.org/10.1007/s11625-014-0258-4

World Bank (2011) World development report 2011: conflict, security and development. World Bank, Washington, DC

Zgambo O (2018) Exploring food system transformation in the greater Cape Town area. Stellenbosch University, Stellenbosch

Publisher's Note Springer Nature remains neutral with regard to jurisdictional claims in published maps and institutional affiliations. 


\section{Affiliations}

\section{Laura Pereira ${ }^{1,2,3}$ (1) Niki Frantzeskaki ${ }^{4}$. Aniek Hebinck ${ }^{5} \cdot$ Lakshmi Charli-Joseph $^{6} \cdot$ Scott Drimie $^{1,7} \cdot$ Michelle Dyer $^{3,8}$. Hallie Eakin ${ }^{9}$. Diego Galafassi ${ }^{3}$. Timos Karpouzoglou ${ }^{10}$ - Fiona Marshall ${ }^{11} \cdot$ Michele-Lee Moore $^{3} \cdot$ Per Olsson $^{3}$. J. Mario Siqueiros-García ${ }^{6,12}$. Patrick van Zwanenberg ${ }^{13}$. Joost M. Vervoort ${ }^{14,15,16}$}

1 Centre for Complex Systems in Transition, Stellenbosch University, Stellenbosch, South Africa

2 Centre for Food Policy, City University of London, Northampton Square, London EC1V 0HB, UK

3 Stockholm Resilience Centre, Stockholm University, Stockholm, Sweden

4 Centre for Urban Transitions, Swinburne University of Technology, Melbourne, Australia

5 DRIFT, Erasmus University Rotterdam, Rotterdam, The Netherlands

6 Laboratorio Nacional de Ciencias de la Sostenibilidad, Instituto de Ecología, Universidad Nacional Autónoma de México, Mexico City, Mexico

7 Southern Africa Food Lab, Stellenbosch University, Stellenbosch, South Africa

8 James Cook University, Townsville, Australia

9 School of Sustainability and Julie Ann Wrigley Global Institute of Sustainability, Arizona State University, Tempe, USA
10 Division of History of Science, Technology and Environment, KTH Royal Institute of Technology, Stockholm, Sweden

11 Science Policy Research Unit, University of Sussex Business School, Brighton, UK

12 Instituto de Investigaciones en Matemáticas Aplicadas y en Sistemas, Unidad Mérida, Universidad Nacional Autónoma de México, Mexico City, Mexico

13 Centro de Investigaciones para la Transformación [CENIT], Universidad Nacional de San Martín, Buenos Aires, Argentina

14 Copernicus Institute of Sustainable Development, Utrecht University, Utrecht, The Netherlands

15 Environmental Change Institute, University of Oxford, Oxford, UK

16 Research Institute of Humanity and Nature, Kyoto, Japan 